\title{
Amankan Ibu dan Anak Bersama Akademisi Dengan Model Pendampingan Continue Of Care di Wilayah Puskesmas Kedungrejo dan Puskesmas Purwoharjo
}

\author{
Vita Raraningrum, Rizky Dwiyanti Yunita \\ Program Studi Diploma Kebidanan Akademi Kesehatan Rustida, Banyuwangi \\ vitarara.11@gmail.com
}

\begin{abstract}
Abstrak
Kegiatan pengabdian kepada masyarakat yang dilakukan oleh dosen program studi Diploma III Kebidanan Akademi Kesehatan Rustida yang dilaksanakan mulai tanggal 10 April 2018, bertempat di wilayah puskesmas kedungrejo, Kec. Muncar, Kab. Banyuwangi dan puskesmas Purwohajro, Kec. Purwoharjo, Kab. Banyuwangi. kegiatan Continue of care merupakan program asuhan kebidanan yang berkesinambungan mulai dari kehamilan, Persalinan, Nifas, Neonatus, dan KB yang bertujuan meningkatkan pengetahuan ibu hamil wilayah puskesmas kedungrejo dan puskesmas purwoharjo dalam hal mendeteksi dini komplikasi resiko tinggu yang mungki dapat terjadi serta mampu beradaptasi dengan perubahan yang terjadi selama hamil. Metode kegiatan ini adalah pendampingan kepada ibu hamil oleh kader dan mahasiswa kepada ibu hamil dengan usia kehamilan memasuki trimester III hingga pengambilan keputusan untuk mengggunaka alat kontrasepsi selama 13 kali kunjungan. Hasil kegiatan ini menunjukkan peningkatan pengetahuan oleh ibu hamil pada trimester III dalam beradaptasi pada masa kehamilan, persiapan persalinan, perawatan masa nifas, perawatan pada neonatus serta mampu memutuskan untuk penggunaan alat kotrasepsi
\end{abstract}

Kata Kunci : Continue Of Care, Pendampingan, Akademisi

\begin{abstract}
This community service activities was carried out by the lecturers from Rustida Health Academy of Midwifery. This activities were starting from April 10, 2018, located in two locations, such as: the Kedungrejo health center area, Sub-district Muncar, Banyuwangi Regency, and Puskesmas Purwoharjo, Sub- District Purwoharjo, Banyuwangi Regency. The 'Continue of Care' program is an assistance program from Midwifery to pregnant mothers. This assistances is starting from pregnancy, childbirth, after-childbirth, neonates, and contraception planning. This program is aimed to increase the knowledge of the mothers about early detection of pregnancy, and early detection of high risk complications which could be happen during the pregnancy. The assistances is done by the students and the cadres to the mothers with early age pregnancy until they agree to take the contraception after 13 visits. The results of this activity showed the higher knowledge from the pregnant women, the mothers, to care their pregnancy and their baby, and the higher number from mothers who decided to use the contraceptive devices.
\end{abstract}

Keywords: Continue of Care, Assistance, Academics

\section{PENDAHULUAN}

Tulisan ini akan membahas tentang masalah kesehatan ibu dan anak khususnya tentang pendampingan pada ibu dan anak dengan menggunakan metode continue of care. Pendampingan pada ibu dengan usia kehamian trimester 3 (36 minggu s.d 40 minggu), persiapan persalinan, perawatan masa nifas dengan program minimal KNl sampai dengan KN4, pengambilan keputusan untuk menggunakan alat kontrasepsi, sedangkan pendampingan yang dilaksanakan kepada neonatus dan bayi adalah saat bayi baru lahir, bayi 
usia 0 hari s.d 40 hari yang telah diprogramkan oleh pemerintah dengan batas mininal mulai dari KN 1 sampai dengan KN 3

Kabupaten banyuwangi masih diliputi dengan isu strategis dari pembangunan kesehatan propinsi jawa timur tahun 2016 ialah (1) Masih tingginya angka kematian ibu melahirkan dan angka kematian bayi, (2) Belum optimalnya penanganan masalah Gizi kepada Ibu Hamil, Bayi dan Balita, (3) Belum optimalnya pelayanan kesehatan bagi penerima bantuan iuran (PBI) masyarakat miskin (4) Masih rendahnya akses masyarakat terhadap Sarana Sanitasi Total Berbasis Masyarakat (STBM), (4) Masih tingginya masalah kesehatan yang disebabkan oleh penyakit menular, penyakit tidak menular dan bencana, (5) Tingginya kasus HIV/AID dan penyalahgunaan Napza di Jatim, (6) Rasio Tenaga kesehatan strategis terhadap jumlah penduduk dan pembiayaan kesehatan yang masih rendah. sedangkan dibanyuwangi sendiri pada bidang kesehatan mempunyai isu strategis, yakni (1) Optimalisasi Kualitas pelayanan, (2) optimalisasi pelayanan kesehatan ibu dan anak, (3) optimalisasi pemberdayaan masyrakat untuk mandiri hidup sehat.

Hasil wawancara dengan beberapa ibu hamil dan bidan wilayah Puskesmas Kedungrejo dan Puskesmas Purwoharjo yang dilakukan pada bulan April 2018, diperoleh informasi bahwa belum optimalnya pendampingan pada ibu hamil normal/resiko tinggi yang dilakukan secara maksimal karena keterbatasan waktu dan medan tempuh serta tidak efektifnya ibu hamil dalam kelas ibu hamil, selama kunjungan bidan hanya menjelaskan apa yang dibutuhkan selama masa hamil dengan media yang dibawa oleh bidan, dalam hal ini ibu merasa kesulitan untuk senantiasa mengingat apa yang telah di jelaskan oleh petugas.

Mempertimbangkan jumlah bidan dan luas dari daerah wilayah Puskesmas Kedungrejo dan Puskesmas Purwoharjo, dengan pemahaman yang masih kurang dalam hal pendampingan, khususnya media buku ajar yang inovatif, maka para akademisi yang sekaligus seorang bidan bersama dengan Puskesmas Kedungrejo dan Puskesmas Purwoharjo dalam pelaksanaan Program Kemitraan Masyarakat (PKM) ini memandang perlu untuk mengadakan kegiatan P3M- PKM yang melibatkan para bidan dan ibu hamil, bahkan masing - masing kepala puskesmas sangat berharap kegiatan ini bisa berlangsung dengan segera. hal ini dikarenakan mereka memerlukan pembaharuan atau up-date untuk keilmuan khususnya kebidanan

\section{METODE PELAKSANAAN}

Kegiatan pengabdian kepada masyarakat ini dilaksanakan selama 4 bulan mulai april 2018 sampai dengan Juli 2018 di wilayah puskesmas kedungrejo Kec. Muncar dan puskesmas purwoharjo kec. purwoharjo. Demi terwujudnya tujuan yang diharapkan maka rencana kegiatan pelatihan dibuat seperti pada gambar berikut :

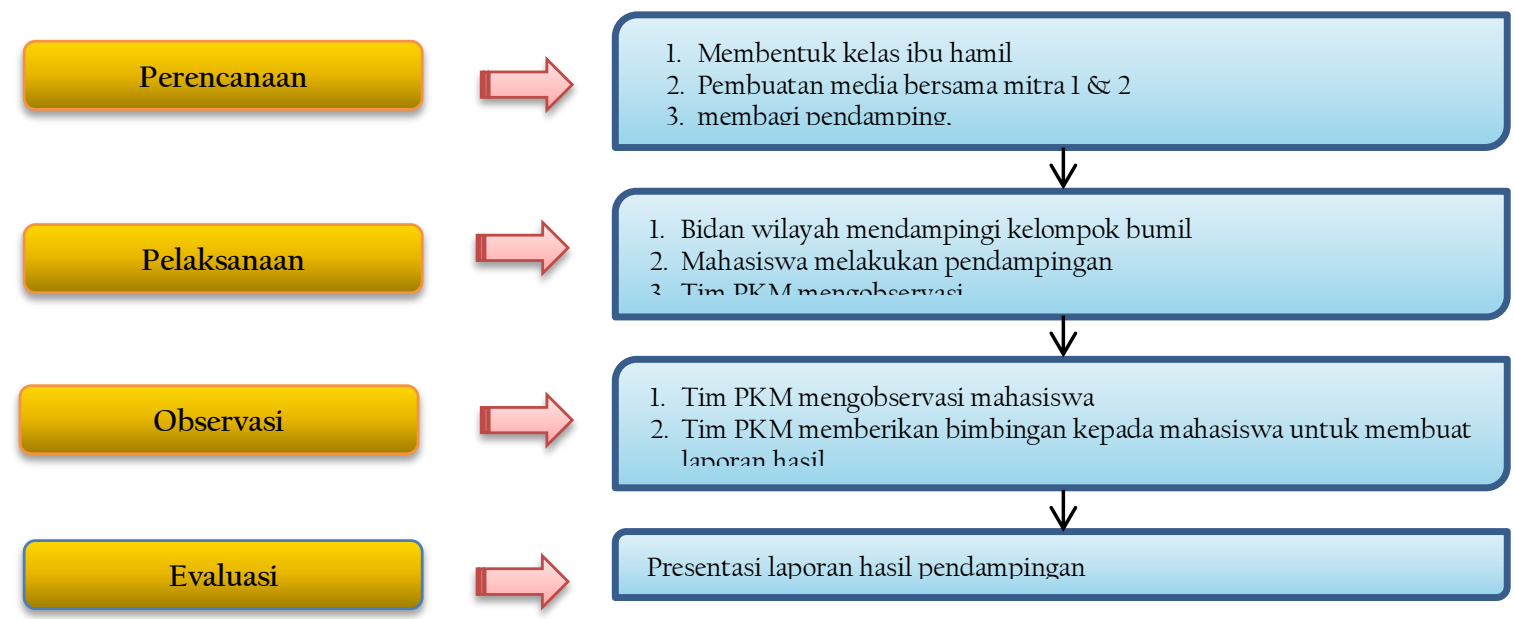

Gambar l. Metode dan Tahapan Pendampingan. 
Pada tahap persiapan dilakukan wawancara dengan pihak puskesmas kedungrejo dan purwoharjo yakni kepala puskesmas dan bidan koordinator. Wawancara dilakukan untuk mendapatkan data yang akan di modelkan dengan metode continue of care. Selain itu pada tahapan ini disepakati bahwa untuk melakukan pendampingan kepada ibu hamil akan melibatkan mahasiswa dan kader posyandu.

Tahapan Pelaksanaan program PKM ini dilaksanakan dalam bentuk program pendidikan kesehatan, pendidikan kesehatan diberikan pada setiap kali kunjungan dilakukan dengan memberdayakan 1 mahasiswa, 1 kader dan 1 ibu hamil. Materi utama pendidikan kesehatan pada ibu dengan resti adalah tanda bahaya kehamilan resiko tinggi, persiapan menjelang persalinan, tanda bahaya dan perawatan masa nifas, perawatan bayi baru lahir dan kontrasepsi. Materi diberikan dalam bentuk penyuluhan dengan media SAP dan metode diskusi serta mendampingi ibu hamil pada setiap kali kunjungan

Evaluasi Pelaksanaan Program dan Keberlanjutan program terus dilakukan oleh tim akademisi pada kegiatan PKM dilapangan agar tehnologi yang telah disampaikan tetap dan terus dilaksanakan oleh masyarakat dikemudian hari atau di tularkan kepada masyarakat lainnya.

Monitoring dan evaluasi dilakukan dengan : Monitoring dan evaluasi dilaksanakan disetiap akhir sesi pada setiap asuhan dari pendampingan untuk mendapatkan peningkatan pengetahuan masyarakat dan mengetahui efektifitas pendampingan, Monitoring dan evaluasi dilakukan oleh tim PKM dan mahasiswa sehingga pendampingan yang dilakukan dapat langsung dibina dibawah puskesmas., Monitoring dan evaluasi dilakukan setiap saat dengan komunikasi oleh tim akes rustida atau mitra secara langsung menggunkan sarana komunikasi yang ada seperti : telepon, sms, whatsapp atau email, Dilakukan pendokumentasian kegiatan monitoring dan evaluasi sebagai dasar mengetahui perkembangan dari pendampingan.

\section{HASIL DAN PEMBAHASAN}

Pendampingan yang bertujuan untuk meningkatkan pengetahuan ibu hamil di wilayah puskesmas kedungrejo dan purwoharjo telah memberikan hasil luaran, hasil yang dimaksud diantaranya adalah :

1. Mengingkatnya kemampuan pengetahuan ibu hamil tentang adaptasi pada masa kehamilan, persiapan persalinan, perawatan masa nifas, perawatan pada neonatus serta mampu memutuskan untuk penggunaan alat kotrasepsi. Pendampingan ibu hamil resiko tinggi dimulai dari pendampingan ibu hamil pada trimester III dengan usia kehamilan > 37 minggu, dengan memeriksa keadaan umum ibu dan memantau kesejahteraan janin hingga menjelang persalinan serta menerapkan tindakan komplementer untuk membantu ibu agar mampu beradaptasi dengan ketidaknyamanan ibu saat trimester III, kunjungan dilakukan selama 2-3 kali semasa kehamilan dan dilanjutkan dengan perawatan nifas hari pertama, perawatan bayi baru lahir usia 0 hari serta pengambilan keputusan menjadi aseptor KB

2. Memberdayakan kader posyandu untuk dapat melaksanakan program pendampingan dengan model continue of care

\section{KESIMPULAN DAN SARAN}

Kesimpulan yang dapat ditarik dari Pengabdian kepada masyarakat Amankan Ibu Dan Anak Bersama Akademisi Dengan Model Pendampingan Continue Of Care Di Wilayah Puskesmas Kedungrejo Dan Puskesmas Purwoharjo terhadap ibu hamil telah berhasil meningkatkan pengetahuan ibu dan memberdayakan kader dan mahasiswa Prodi D.III Kebidanan Akademi Kesehatan Rustida. Dengan kerjasama tim pengabdian yang baik dan peran serta akftif dari mahasiswa atau dosen sebagai penyuluh/ narasumber dalam kegiatan pengabdian, semoga dapat memberikan manfaat bagi mitra pengabdian masyarakat dalam keberlanjutan 
pendampingan pada ibu hamil di Wilayah Puskesmas Kedungrejo dan Puskesmas Purwoharjo. Pengabdian yang kami lakukan ini telah sampai pada tahap dilaksanakannya kegiatan penyuluhan tentang tanda bahaya, pencegahan serta persiapan menghadapi persalinan

Perlu adanya upaya upaya untuk keberlanjutan program ini. besarnya permintaan pasar terhadap tenaga kesehatan yang terampil dalam melakukan asuhan kebidanan kepada masyarakat khususnya kesehatan ibu dan anak, menjadi gerbang intansi kesehatan untuk dapat memberdayakan potensi yang masih tertidur seperti mahasiswa dan kader yang masih belum maksimal dalam memberikan asuhan kepada ibu dan anak.

\section{UCAPAN TERIMA KASIH}

1. Lembagan Penelitian Dan Pengabdian Masyarakat Akademi Kesehatan Rustida

2. Kepala Puskesmas Kedungrejo Kec. Muncar Dan Kepala Puskesmas Purwoharjo Kec. Purwoharjo

3. Pihak - pihak lain yang terkait

\section{DAFTAR PUSTAKA}

Dinkes Banyuwangi, Tahun 2015, Kebijakan Dan Strategi Kesehatan Ibu Dan Anak Di Kabupaten Banyuwangi, Dinas kesehatan Kab. Banyuwangi

Parwati, N.N. \& Mariawan, I. M.,2008; Pelatihan tindakan kelas untuk guru - guru SD dikabupaten tabanan. Laporan P2M. Tidak diterbitkan. Singaraja : Undiksha

Dick, W., Carey, L., \& Carey, J. O, 2001; The Systematic Design Of Instruction. USA : Addisonwesley educational publisher Inc.

Gall, M. D., Gall, J. P., \& Borg, W. R, 2008; Educational Research: An Introduction $\left(7^{\text {th }}\right)$. New York : Longman

\section{Lampiran Gambar}

Kunjungan ke l (03-05-18)

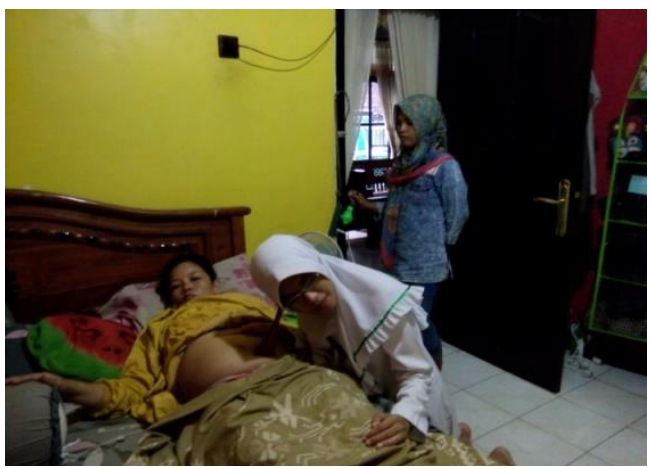

Kunjungan ke 3 (10-05-18)

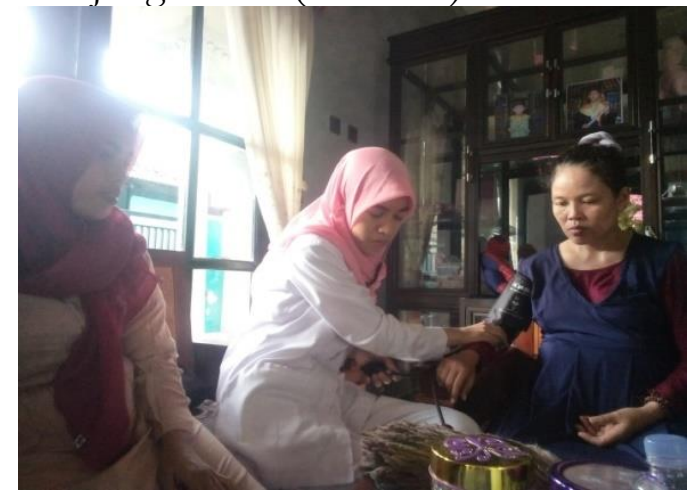

Kunjungan ke 2 (08-05-18)

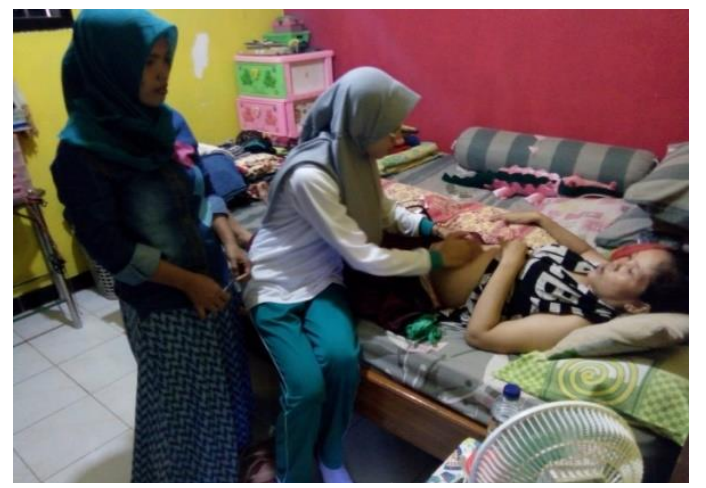

Kunjungan ke 4 (11-05-18)

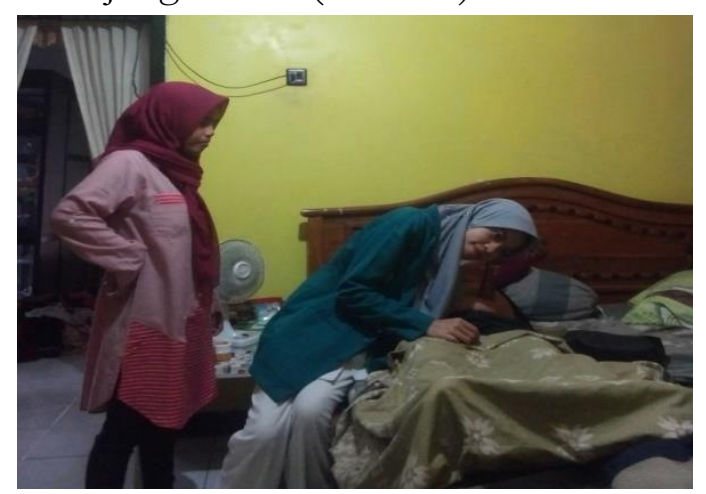


Kunjungan ke 5 (16-05-18)

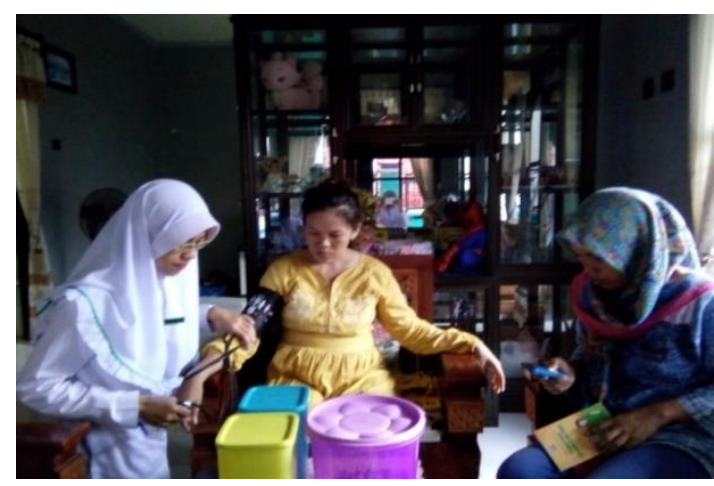

Kunjungan ke 7 (24-05-18)

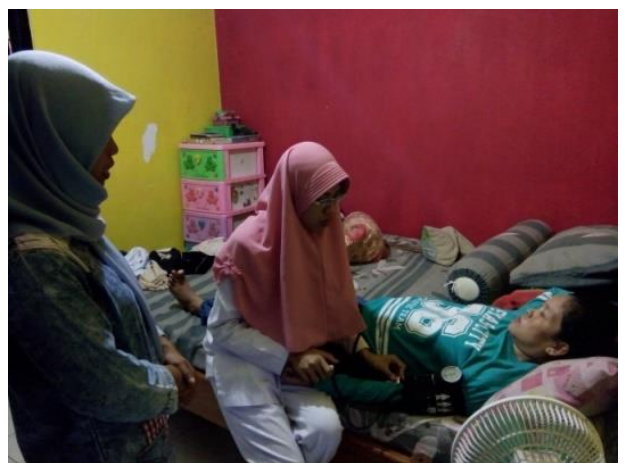

Kunjungan 9 (30-05-18)

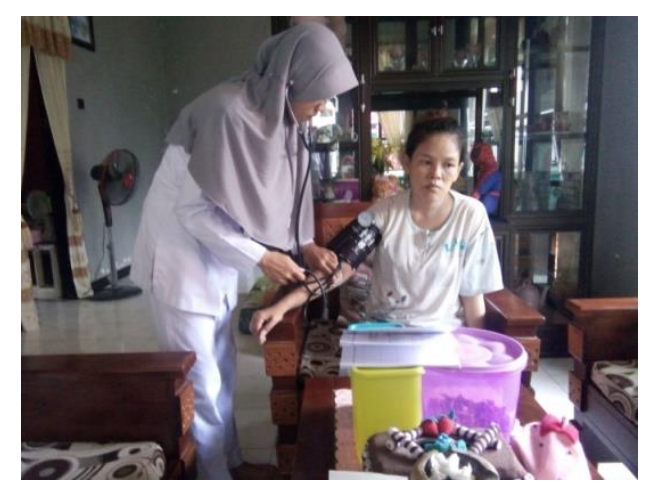

Kunjungan 11 (05- $06-2018)$

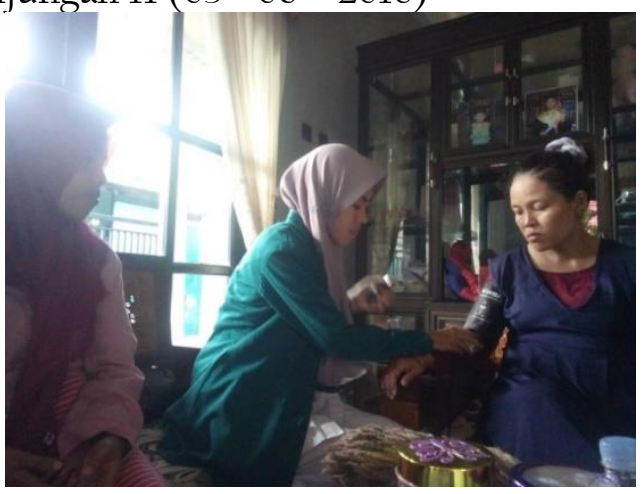

Kunjungan ke 6 (19-05-18)

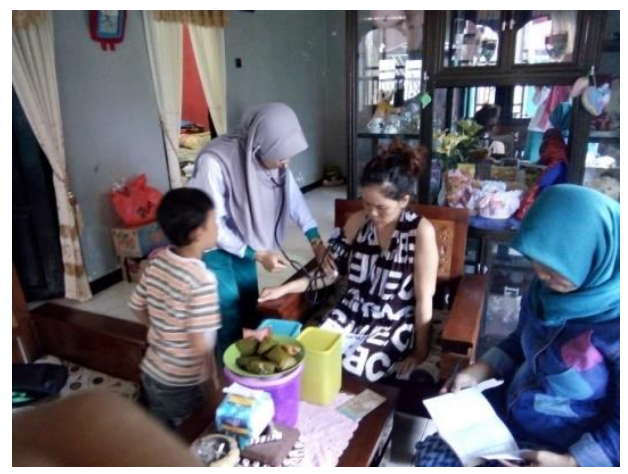

Kunjungan ke 8 (27-05-18)

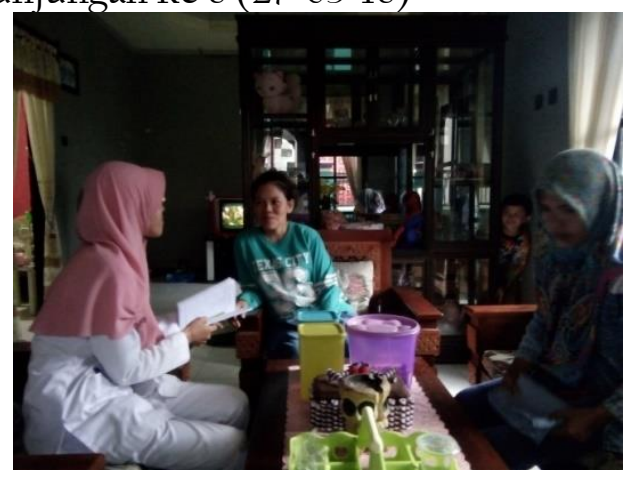

Kunjungan 10 (02-06-18)

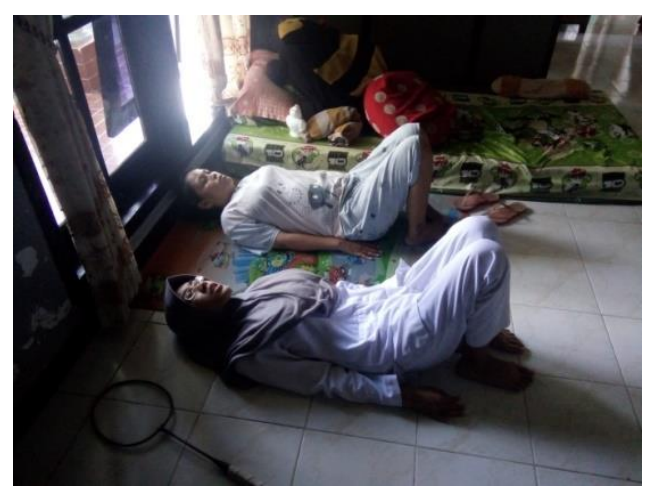

Kunjungan $12(11-06-2018)$

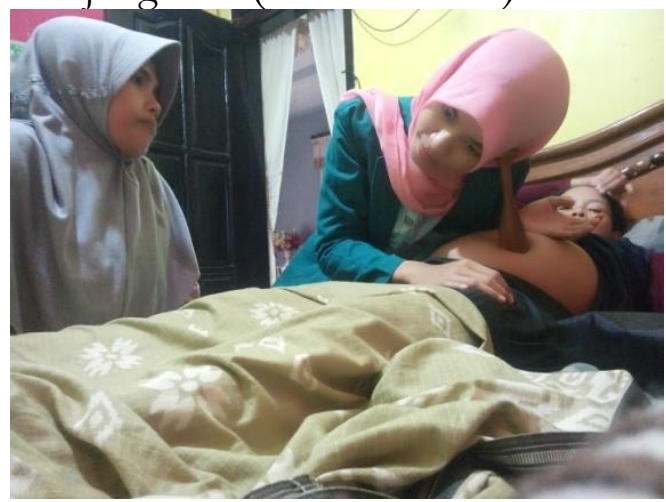


Kunjungan 13 (13-06-2018)
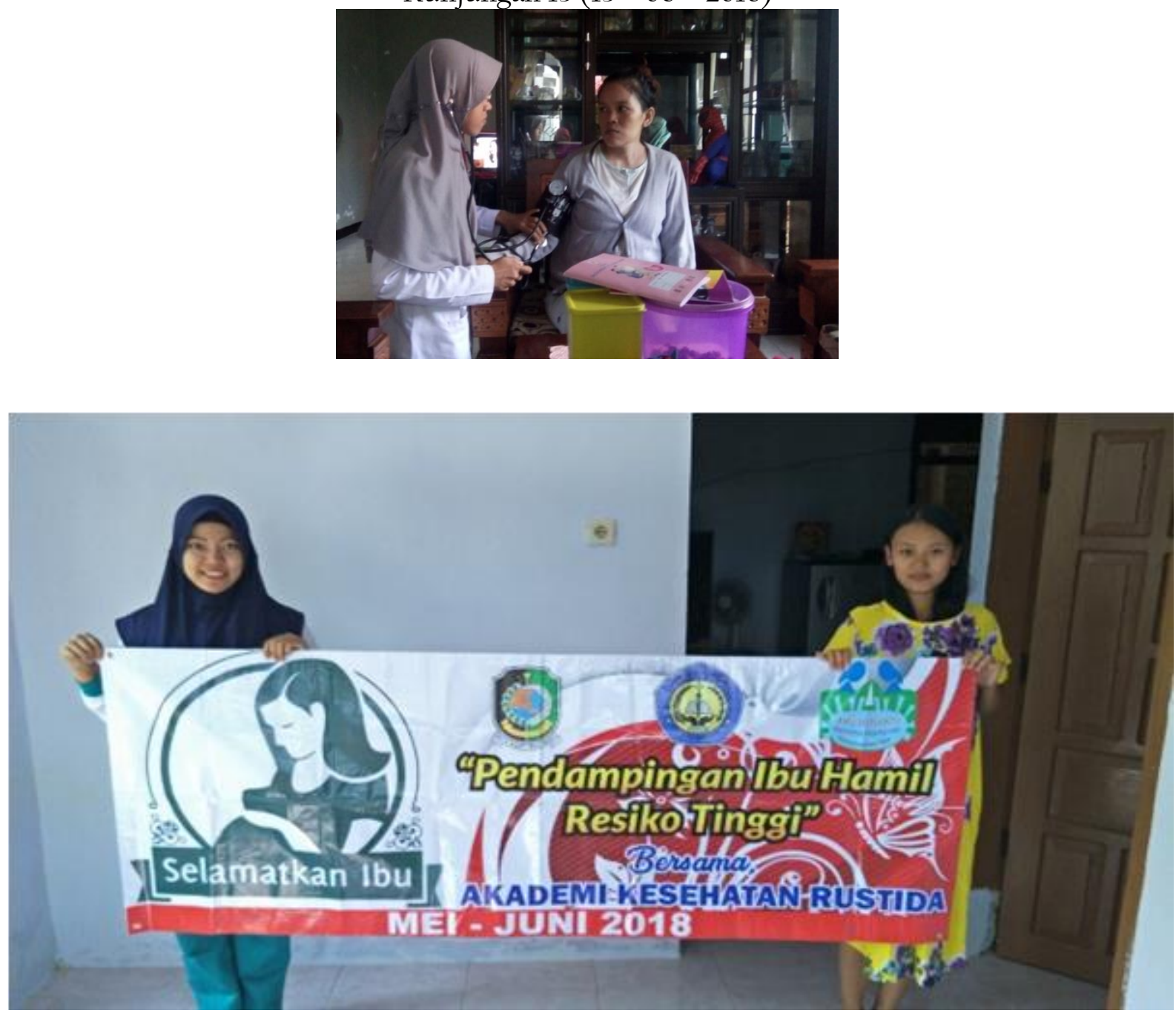